\title{
Conteúdos digitais multimídia: o foco na usabilidade e acessibilidade
}

\begin{abstract}
Elisabeth Fátima Torres
Doutora em engenharia, UFSC

E-mail: eftorres@terra.com.br
\end{abstract}

Alberto Angel Mazzoni

Doutor em engenharia, UFSC

E-mail: amazzoni@terra.com.br

\section{Resumo}

Abordam-se aspectos referentes à usabilidade e acessibilidade de conteúdos digitais multimídia.

São analisados os princípios do projeto de produtos baseados na usabilidade que se aplicam à produção desses documentos digitais, inovando-se ao interpretar os princípios de usabilidade sob o enfoque da acessibilidade. Os cuidados que devem ser tomados para que os documentos digitais adquiram as qualidades da usabilidade e da acessibilidade são assinalados. Uma ênfase especial é dada às situações relacionadas à interação, mediante a utilização de ajudas técnicas, com a informação disponibilizada no espaço digital.

\section{Palavras-chave}

Conteúdos digitais; Acessibilidade; Usabilidade; Ajudas técnicas; Sistemas de leitura de tela; Espaço digital.

\section{Multimedia digital contents: an approach on usability and accessibility}

\begin{abstract}
Aspects related to the usability and accessibility of multimedia digital contents are discussed. The principles of the project of products, based on the usability are analyzed and considered with reference to the application of the same ones to production of digital documents. The innovation consists in the interpretation of the usability principles under the focus of the accessibility. The cares which must be taken for the digital documents to have usability and accessibility quality are pointed out. A special emphasis is laid on the situations related to the interaction, by use of technical aids, with information which are available in the digital space.
\end{abstract}

\section{Keywords}

Digital contents; Accessibility; Usability; Technical aids; Screen readers, Digital space.

\section{INTRODUCุÃO}

Um conteúdo é uma forma semiologicamente interpretável, desenvolvida em determinado formato e que adquire significado devido aos antecedentes socioculturais das pessoas que acessam. Ou seja, um conteúdo torna-se importante devido ao valor de uso que ele representa para o seu destinatário (Ruiz-Velasco, 2003). Um conteúdo digital é assim caracterizado por estarem as suas informações codificadas em binário e serem processadas através de sistemas informáticos digitais.

No projeto de conteúdos digitais multimídia, ou hipermídia, a serem usados com objetivos de aprendizagem, deve-se observar dois critérios de qualidade para os mesmos: a usabilidade e a acessibilidade.

A usabilidade de um produto pode ser mensurada, formalmente, e compreendida, intuitivamente, como sendo o grau de facilidade de uso desse produto para um usuário que ainda não esteja familiarizado com o mesmo. A ISO* define a usabilidade em função da eficiência, eficácia e satisfação com a qual os usuários podem alcançar seus objetivos em ambientes específicos, quando utilizam determinado produto ou serviço.

Observar a acessibilidade de um produto consiste em considerar a diversidade de seus possíveis usuários e as peculiaridades da interação dessas pessoas com o produto, o que pode se manifestar tanto nas preferências do usuário (exemplo: o que prefere ler a ouvir), quanto nas restrições à qualidade do equipamento utilizado (exemplo: um usuário cuja impressora só trabalha com preto e branco), ou, até mesmo na existência de necessidades educativas especiais que não podem ser ignoradas pelos desenvolvedores do produto (exemplo: entre os usuários pode haver alguns que não ouçam os sons, conseqüentemente, mensagens sonoras são inadequadas para eles).

* International Standard Organization, norma ISO 9999 
Como assinala Gutiérrez y Restrepo (2003), a acessibilidade deve ser considerada como um conceito absoluto. Ela independe da ajuda técnica* (software ou hardware) que o usuário utiliza e da limitação orgânica ele possua. Por exemplo: o fato de determinado conteúdo digital apresentar-se como acessível quando se trabalha com determinada versão de um leitor de telas e com um navegador de Internet específico não comprova que esse produto tenha a qualidade da acessibilidade, pois ele pode apresentar-se como inacessível para diferentes usuários que utilizem produtos de outros fabricantes, e até mesmo versões diferentes do mesmo software de leitura de tela. Da mesma maneira, não se pode asseverar a acessibilidade de um conteúdo digital em função das necessidades de usuários específicos, ou seja, não se pode afirmar que um produto é acessível apenas pelo fato de que pessoas com determinada limitação consigam interagir com esse produto.

A acessibilidade é uma qualidade que se comprova a partir da satisfação de determinados requisitos, os quais estão especificados pelo W3C ${ }^{* *}$. Selos de qualidade têm sido criados por algumas entidades para assinalar a qualidade do produto que está sendo adquirido ou utilizado. Para a avaliação de páginas Web, existem vários desses selos, como os apresentados na figura 1, na qual consta o selo de certificação do Bobby, pioneiro no tema, e o selo do W3C, disponibilizado em três graus distintos de qualidade e reconhecido internacionalmente.

A usabilidade e a acessibilidade são características que agregam qualidade a um produto conteúdo digital, e ambas são direitos do consumidor que compra esse produto. A usabilidade visa a satisfazer um público específico, definido como o consumidor que se quer alcançar quando se define o projeto do produto, o que permite que se trabalhe com as peculiaridades adequadas a esse público-alvo (associadas a fatores tais como a faixa etária, nível socioeconômico, gênero e outros). Porém, é a acessibilidade que permitirá que a base de usuários projetada seja alcançada em sua máxima extensão e que os usuários que se deseja conquistar com o produto tenham êxito em iniciativas de acesso ao conteúdo digital em uso.

\footnotetext{
* Considera-se como ajuda técnica qualquer produto, instrumento, equipamento ou sistema técnico utilizado por uma pessoa com deficiência, fabricado especificamente ou disponível no mercado, criado para prevenir, compensar, mitigar ou neutralizar a deficiência, a limitação à atividade e a restrição à participação dessa pessoa. Essa definição corresponde à aplicação do conceito apresentado pela ISO estritamente às pessoas com limitações oriundas de deficiência.

** W3C - World Wide Web Consortium http://www.w3.org/WAI
}

FIGURA 1

Selos que comprovam a acessibilidade de páginas web

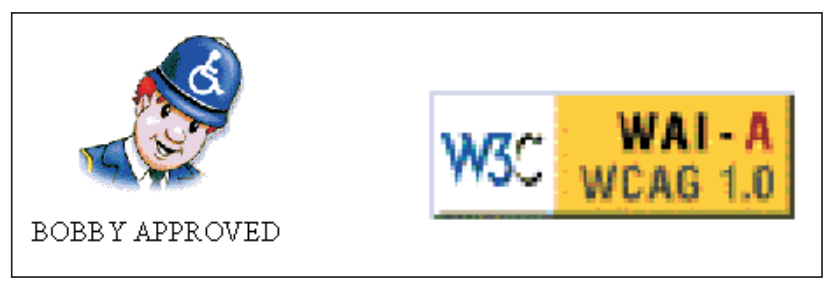

As possibilidades que este novo espaço, o digital ${ }^{*}$, criado pelas tecnologias de informação e comunicação, proporciona para o atendimento às distintas formas de interação das pessoas com a informação, respeitando tanto as suas preferências e as limitações (tanto aquelas relacionadas aos equipamentos utilizados quanto as associadas às características orgânicas dos usuários desses equipamentos), são apresentadas ao longo do texto. Aqui, discutir a usabilidade e a acessibilidade de conteúdos digitais corresponde a aplicar os princípios do Design for all $^{* *}$, o desenho para todos, ao conteúdo digital em análise, pois todas as pessoas (independentemente da tecnologia que utilizem e do fato de ter, ou não, limitações oriundas de deficiência) são beneficiadas pela aplicação desses princípios.

Este artigo analisa algumas características de usabilidade que podem ser incorporadas ao projeto de um conteúdo digital multimídia e, considerando-se que este tipo de documento está sujeito a ser propagado pelo espaço digital, seja com interação on-line ou off-line, podendo alcançar assim a usuários com distintas necessidades, estabelece o vínculo entre a usabilidade e a acessibilidade de um documento. $\mathrm{O}$ texto tem como objetivo analisar os conteúdos digitais multimídia, principalmente os de caráter educativo ou informativo, tendo como suporte teórico os princípios adotados no projeto de produtos baseados na usabilidade. Por outra parte, com a proposta deste trabalho, objetiva-se que seja estabelecido um vínculo - permanente - entre a usabilidade e a acessibilidade a esses conteúdos digitais.

\section{CONTEÚDOS DIGITAIS}

Que se entende por conteúdo digital? É a informação apresentada na forma digitalizada, organizada para transmitir conhecimentos, em níveis de profundidade

\footnotetext{
* Conceito apresentado no artigo "A acessibilidade à informação no espaço digital” publicado pelos autores na revista Ciência da Informação, v.31, n.3, p.83 - 91, 2002.

** Design for all (desenho para todos) é um conceito que envolve a concepção, desenvolvimento e comercialização de produtos e serviços correntes, de sistemas e ambientes que sejam acessíveis e utilizáveis por um conjunto de usuários o mais vasto possível.
} 
específicos, sobre determinado tema. Os conteúdos digitais produzidos com propósitos educativos, ou informativos, tendem a ser aperfeiçoados em um processo dinâmico relacionado às necessidades dos seus usuários.

Um conteúdo digital acessível é aquele que pode ser acessado e compreendido por todos os seus usuários. Dentre os documentos digitais, há de se destacar a importância dos que atuam como equivalentes textuais para os elementos não-textuais do documento, tais como os elementos multimídia. Os equivalentes textuais devem proporcionar todas as informações necessárias para a compreensão do conteúdo apresentado no documento.

\section{O desenho para todos no espaço digital}

Construir um conteúdo digital desenhado para todos implica que as informações principais a ele associadas devem estar disponíveis às pessoas, respeitando-se as limitações (tanto orgânicas quanto de equipamento) que essas pessoas possam ter. Para que isso se realize são necessários dois cuidados: permitir que seja possível aceder a esse conteúdo por meio de tecnologias mais simples e apresentar alternativas quanto à forma em que o usuário possa acessar as informações.

A flexibilização da apresentação em formas distintas, que apresentem correspondência em termos de conteúdo, deve ser considerada tanto como uma questão de necessidade quanto de preferência de alguns usuários. A necessidade pode se manifestar pela impossibilidade de aceder à informação divulgada de uma única forma, sempre que ela se torna inacessível, seja devido às características técnicas dos equipamentos (qualidade e custo das tecnologias utilizadas), ou pelas características orgânicas do usuário (por exemplo: deficiências sensoriais, problemas de coordenação motora etc.). A preferência se manifesta quando os usuários optam por ter o acesso à informação pela mídia que mais lhes convém ou agrada, conforme seu estilo de aprendizagem e a tecnologia que utilizem.

Embora ainda não existam mecanismos intergovernamentais que promovam a acessibilidade a conteúdos disponibilizados via Internet, alguns países vêm adotando políticas nesse sentido, particularmente no que diz respeito aos sítios Web de repartições públicas. Satisfazer as diretivas do W3C para a acessibilidade em páginas Web é reconhecido internacionalmente como padrão de qualidade, mesmo naqueles países que ainda não definiram normas sobre esse assunto. Há de se observar que muitas das recomendações apresentadas para obter a acessibilidade na Internet são aplicáveis também à produção de conteúdos digitais.

\section{A acessibilidade no espaço digital}

A acessibilidade no espaço digital consiste em tornar disponível ao usuário, de forma a que possa aceder a ela com autonomia, toda a informação que lhe for franqueável (ou seja, informação para a qual tenha código de acesso ou seja de acesso livre para todos), independentemente de suas características orgânicas, sem prejuízos quanto ao conteúdo da informação. A acessibilidade é obtida combinando-se a apresentação da informação de formas múltiplas (seja com uma simples redundância, ou utilizando-se um sistema automático de transcrição de mídias), com o uso de ajudas técnicas (tais como sistemas de leitura de tela, sistemas de reconhecimento da fala, simuladores de teclado etc.) que maximizam as habilidades dos usuários com limitações associadas a deficiências orgânicas.

A não-observância dos princípios do design for all no espaço digital, pelos autores dos materiais disponibilizados nessa forma, pode ser considerada como uma discriminação feita a milhares de usuários, quantidade que se torna não-mensurável quando a informação aparece em sítios Web de acesso livre.

A informação que não é divulgada ou que não pode ser captada de forma redundante não é realmente acessível. A redundância é obtida quando se contempla a existência de equivalente textual para os conteúdos divulgados por meio de imagens ou de sons, ou seja, deve-se combinar o uso do som com texto, e as imagens, quando usadas, em forma estática ou dinâmica, também devem ter um correspondente textual.

As possibilidades de utilização dos recursos multimídia trazem grandes contribuições para a produção de conteúdos didáticos digitais, permitindo o respeito ao estilo de aprendizagem dos usuários e às suas preferências quanto à forma de recepção da informação. Contudo, é necessário lembrar que há um grupo importante de usuários com problemas de coordenação motora, ou com formas diferentes de percepção sensorial, para os quais o critério estético pode ser um obstáculo, e que as opções disponibilizadas pelos desenvolvedores desses produtos, quanto à recepção da informação, podem constituir uma discriminação ao grupo.

Quando o conteúdo alternativo textual apresentado transmite todas as informações relevantes do conteúdo original (seja sonoro ou visual), pode-se considerar que foi obtido um equivalente textual para ele. Os equivalentes textuais são textos alternativos acessíveis e podem estar expostos no documento-padrão, caracterizando-se, assim, como um recurso de redundância propiciado pelo 
produto (como o uso de legendas mais detalhadas que façam a descrição das figuras apresentadas), ou então estar ocultos e contidos na estrutura do documento, de forma que sejam acessados pelos sistemas de leitura de tela. Quando um sistema desse tipo encontra uma imagem em um documento digital, ele, por si, não pode descrever a imagem para o usuário. É necessário que o autor do documento tenha tomado essa precaução, disponibilizando para tanto um texto alternativo.

Na figura 2, observa-se um exemplo de conteúdo alternativo textual, na forma de descrição oculta, contida no curso "Boas Práticas", de autoria de Berlenga (2000).

Alguns conteúdos digitais contém animações e sons, e os mesmos também devem passar por uma transformação harmoniosa para oferecerem acessibilidade aos seus usuários. A descrição em formato texto, nesses casos, faz-se também necessária. Nesse curso de autoria de Berlenga (2000), que apresentamos como exemplo, além da opção de assistir a um vídeo com entrevista, pode-se acessar arquivos contendo a transcrição em texto de todas as entrevistas apresentadas no curso.

Princípios do projeto de produtos baseados na usabilidade na produção de conteúdos digitais

Os dez princípios relacionados por Jordan (1998) são considerados no projeto de produtos baseados na usabilidade e podem, ser aplicados, com proveito também na produção de documentos digitais multimídia. Esses princípios são retomados nesta análise, na qual se inova ao interpretá-los sob o enfoque da acessibilidade, evidenciando assim os aspectos que podem interferir na qualidade dos conteúdos digitais produzidos com propósitos educativos ou informativos.

\section{Consistência}

Este princípio adverte que, quando um usuário adquire experiência em um produto, ele usa os conhecimentos referentes à realização de uma tarefa para a realização de novas tarefas, procurando assim, com ações similares, atingir novos objetivos.

Para atender a esse princípio, os conteúdos digitais que tenham propósito informativo ou didático, quando divididos em módulos, devem guardar semelhança entre si, tanto no esquema gráfico e na estrutura, quanto na execução das tarefas necessárias na interação com o ambiente. Esse cuidado evita desperdício de tempo com a exploração e identificação do ambiente, e a existência de um padrão traz facilidades para que pessoas com deficiências cognitivas possam utilizar o produto.
FIGURA 2

Exemplo de conteúdo alternativo textual

Fatores comuns às práticas de sucesso

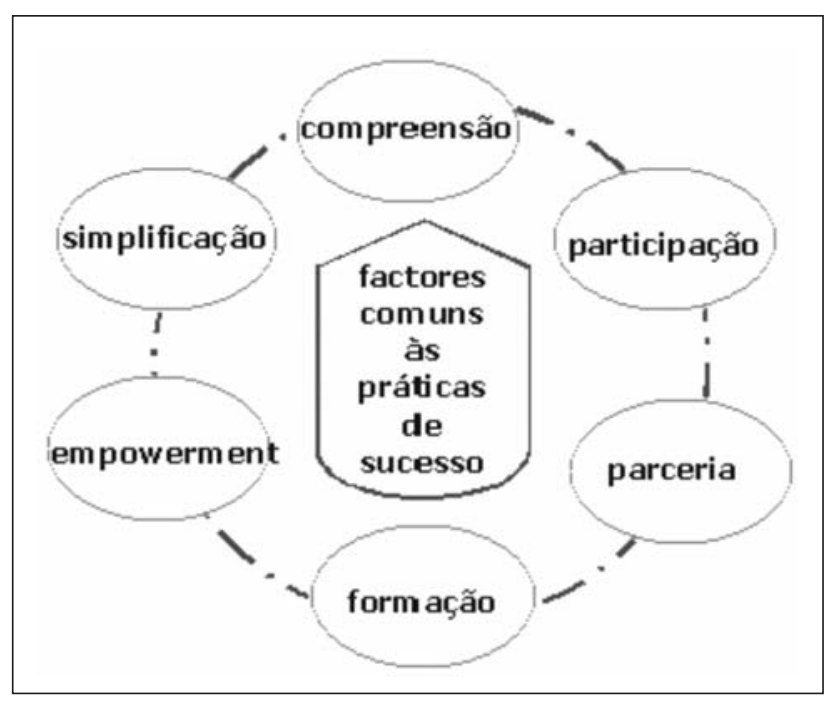

Texto contido na legenda oculta: Figura que representa os fatores comuns às práticas de sucesso. Eles se distribuem em um círculo de 6 balões, e dentro de cada balão surge um fator: a compreensão, a participação, a parceria, a formação, o empowerment, e a simplificação.

\section{Compatibilidade}

Embora guarde semelhança com o conceito de consistência a compatibilidade diz respeito a conhecimento externo ao produto. O princípio adverte que o usuário leva para a interação com o produto conteúdo digital com o qual está interagindo os conhecimentos adquiridos na interação com outros softwares e, também, conhecimentos adquiridos em outras situações do cotidiano, como, por exemplo, a associação de luzes vermelhas com situações de perigo.

Na preparação de materiais didáticos, é fundamental respeitar a cultura dos usuários, e, na preparação de conteúdos digitais didáticos, isto se reflete tanto no léxico e estrutura gramatical utilizada, como nos próprios temas. Os hábitos adquiridos interferem na interação do usuário com o produto, e por isso é aconselhável que os elementos gráficos desse ambiente, tais como a disposição de barras de menu e de ferramentas, guardem semelhança com a interface do sistema operacional ou plataforma em uso, pois os usuários tendem a trabalhar fazendo analogias com atividades desenvolvidas em outros ambientes. É por isso que o usuário com experiência em interfaces amigáveis tem a expectativa de que haja atalhos para os comandos, que exista alguma forma de "Ajuda" que possa interagir com o ambiente sem utilizar o mouse, que o sistema de leitura de tela 
que utiliza encontre o ambiente desse conteúdo digital acessível, e assim por diante.

\section{Consideração dos recursos do usuário}

Este princípio adverte para a necessidade de que sejam evitadas as sobrecargas sensoriais do usuário, respeitandose sua forma de percepção além de considerar o seguinte:

- a possibilidade de que ele possua limitações associadas a deficiências orgânicas distintas, tais como a cegueira, a baixa visão, o daltonismo, a surdez, a epilepsia fotossensível, a coordenação motora pequena ou ausente e outras;

- a forma peculiar de interação do usuário com o conteúdo digital, ou seja, quais são os recursos de software e hardware que ele utiliza nesse acesso.

Este princípio orienta que, se as pessoas estiverem expostas a muitas informações, sob determinado sentido (por exemplo, a visão), deve-se comunicar a ocorrência de eventos importantes usando outra forma de estímulo, ou então, evidenciando a importância do evento. Em situações de muita exposição a estímulos visuais, os estímulos sonoros podem ser uma boa solução para a comunicação. Contudo, há de se considerar também outras categorias de usuários, como aqueles com deficiência visual ou auditiva e, nesses casos, o conteúdo digital deve ser projetado de forma tal que seja possível evidenciar, com sons atrativos, os eventos significativos que ocorrem em ambientes nos quais os usuários já estão acessando os conteúdos pelo som e, da mesma forma, evidenciar uma forma visual facilmente percebível, outros eventos que ocorrem em ambientes nos quais os usuários estão acessando os conteúdos explorando o sentido da visão.

Em respeito a isso se deve, na concepção de conteúdos digitais, evitar soluções que impliquem código proprietário, como, por exemplo, a distribuição de arquivos em formatos que necessitem de software específico de determinada marca comercial de processador de textos. É aconselhável, também, usar arquivos que tenham maior portabilidade, como, por exemplo, os formatos RTF ou TXT, no caso de textos, ou utilizar formatos associados a software de uso livre.

A multimídia deve ser usada como recurso didático e de redundância, cuidando-se sempre, porém, para evitar que o usuário esteja exposto a sobrecargas sensoriais.

Nas próximas figuras, são apresentadas duas versões diferentes para a mesma apresentação, recurso de uso freqüente em conteúdos digitais educativos, havendo em
FIGURA 3

Apresentação não-acessível

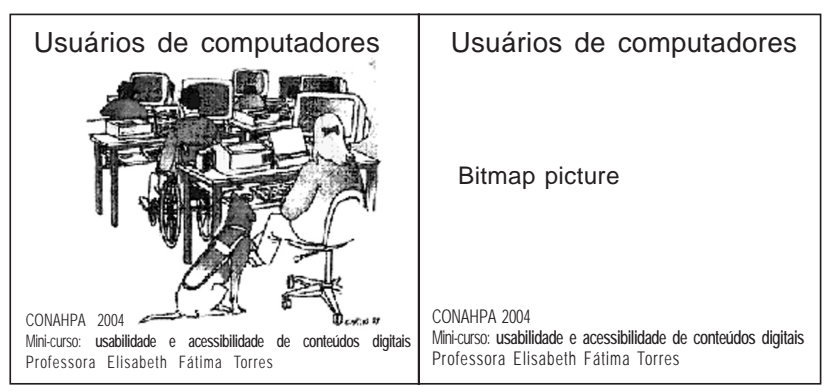

Informação captada por videntes

uma delas uma situação de desrespeito aos recursos do usuário, fato que ocorre quando não existe a preocupação com a verificação da acessibilidade do conteúdo gerado. As apresentações utilizadas como exemplo constam do curso "Usabilidade e Acessibilidade de Conteúdos Digitais”, de autoria de Torres (2004).

Na figura 3, à esquerda, na qual há uma tela de apresentação contendo muita informação visual com título, subtítulos e ilustração), apresenta-se como a informação é captada pelos usuários videntes, e à direita como ela é captada por usuários que acedem à informação utilizando sistemas de leitura de tela (SLT). A ilustração à direita demonstra que apenas os títulos e subtítulos utilizados foram captados e que nenhuma das informações contidas na ilustração foi transmitida ao usuário. Esta apresentação foi elaborada sem a observação aos requisitos de acessibilidade. Neste tipo de apresentação, quando estiver acessando o conteúdo interagindo diretamente com o computador através de um SLT e sem o auxílio de pessoa, o usuário fica sujeito à perda de informações importantes.

A figura 4, a seguir, representa uma alternativa para a mesma apresentação, com a diferença de que, nessa versão, houve respeito à forma de percepção dos possíveis usuários e preocupação em utilizar soluções que conduzam à acessibilidade, como a adoção de legendas ocultas para a descrição da imagem. A coluna à direita exemplifica como o mesmo conteúdo poderá se tornar acessível a usuários com deficiência visual que acessam o conteúdo digital por meio de sistemas de leitura de tela, pois foi utilizado o recurso de descrição da ilustração com a construção de legenda oculta.

Ci. Inf., Brasília, v. 33, n. 2, p. 152-160, maio/ago. 2004 


\section{Feedback}

Conteúdos digitais não-acessíveis proporcionam ausência de feedback a quem os acessa mediante ajudas técnicas. Quando esses documentos estão em formato de hipertexto, por exemplo, podem ser caracterizados como navegação à deriva, pois os usuários que utilizam sistemas de leitura de tela não obtêm informações úteis sobre os mesmos, nem sobre a estrutura do documento, nem sobre as informações apresentadas na tela inicial. Documentos de hipertexto precisam ser construídos respeitando-se a estrutura do documento e as denominações atribuídas aos campos de enlace, pois essas informações são os guias para a navegação dos usuários que utilizam SLT.

Em situações de práticas educativas, deve-se cuidar para que o feedback seja disponibilizado com redundância, usando, simultaneamente, conforme a preferência do usuário, tanto o texto quanto som e imagens. A ausência de feedback, ou a demora na obtenção no mesmo, pode induzir os usuários a suspeitar de uma falha no sistema, e disso podem resultar ações que sejam prejudiciais aos processos em andamento.

\section{Prevenção e recuperação de erros}

É possivel que, devido a falhas na concepção do ambiente do conteúdo digital ou, até mesmo, devido à pouca familiaridade com ambientes informatizados, o usuário determine a execução de ações que não são as desejadas por ele. Para evitar isso, é aconselhável confirmar as ações de resultados mais determinantes, como, por exemplo, "sair do programa" via caixas de diálogo.

Por uma questão de compatibilidade com outros ambientes de trabalho digitais, o usuário geralmente tem a expectativa de que seus erros, ou ações indesejadas, possam ser desfeitos. É necessário diferenciar os possíveis erros do usuário das falhas que estão associadas com a compatibilidade do produto, as quais podem ocorrer, por exemplo, devido à denominação inadequada de comandos, à ausência de rótulos, ao uso de ícones dissociados de significado ou de significado dúbio, ou à existência de campos de enlace sem conteúdo semântico.

Ci. Inf., Brasília, v. 33, n. 2, p. 152-160, maio/ago. 2004
Usuários de computadores

Figura representando algumas pessoas trabalhando com computadores.

Em primeiro plano aparece uma mulher trabalhando em seu micro enquanto um cão guia repousa ao seu lado. Em outro plano, é possível observar um usuário em cadeira de rodas.

CONAHPA 2004

Mini-curso: usabilidade e acessibilidade de conteúdos digitais Professora Elisabeth Fátima Torres

ssora Elisabeth Fátima Torres

Informação captada por videntes

Informação captada com SLT

FIGURA 5

Exemplo de sítio Web que permite o controle do usuário

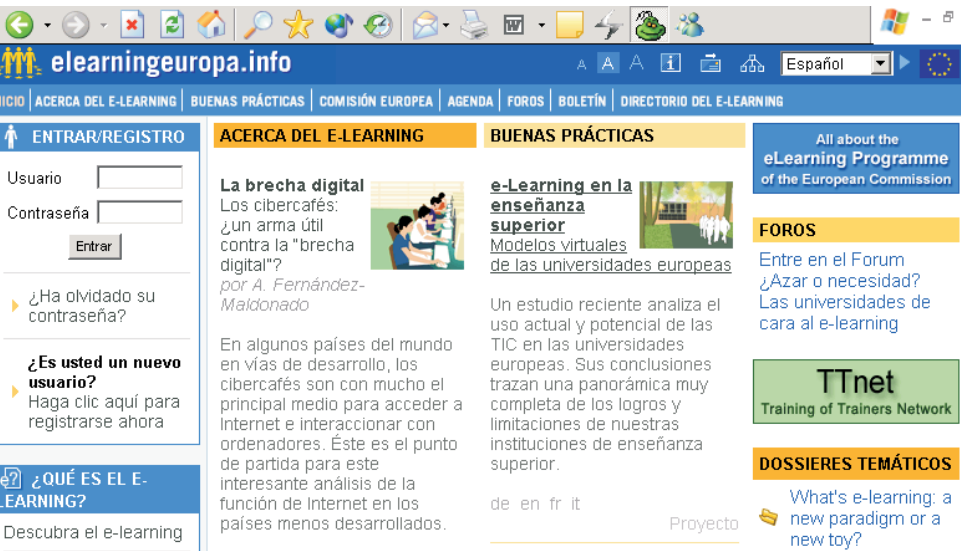

\section{Controle do usuário}

Este princípio determina que os produtos devem ser projetados de forma tal que seja permitido ao usuário ter o máximo de controle possível na sua interação com determinado produto.

Significa permitir que o usuário possa fazer as adaptações a ele adequadas para a utilização do produto, desde ajustes no conteúdo em exibição, tais como efeitos de ampliação, parar animações, modificar contraste, optar entre o uso monocromático ou policromático etc. Opções quanto à forma de recebimento de arquivos com conteúdos que integram o documento principal são também desejáveis. Por exemplo: que seja possível optar em abaixar o arquivo completo de um documento em hipertexto em vez de fazer a navegação on-line, conectado à Internet. Conteúdos digitais associados a cursos que envolvam várias sessões de interação devem guardar as preferências dos usuários, para que eles possam ter esses ajustes à disposição, em suas posteriores interações com o sistema. Na figura 5, apresenta-se o 


\section{Elisabeth Fátima Torres / Alberto Angel Mazzoni}

conteúdo de um sítio Web, o elearningeuropa.info, o qual guarda as preferências dos usuários e lhes possibilita estabelecer alguns controles, desde os relativos ao tamanho da fonte dos textos, como a opção quanto ao idioma em que se prefere ter acesso à informação.

É sempre desejável que o usuário possa escolher o formato no qual prefere receber e trabalhar com os conteúdos do curso. Deve-se cuidar para que os textos importantes estejam livres do recurso de rolagem automática, ou então que haja facilidades para que o usuário possa desativar essa rolagem. A rolagem prejudica tanto as pessoas com deficiência visual quanto as com deficiência cognitiva.

\section{Clareza da informação apresentada}

Embora Jordan (1998) tenha chamado este princípio de clareza visual, é mais adequado denominá-lo, no contexto de conteúdos digitais que tenham propósito didático ou informativo, clareza da informação apresentada, respeitando-se, assim, as diferenças de percepção sensorial existente entre as pessoas. Clareza é utilizada referindo-se à qualidade e à precisão da informação transmitida, a qual deverá ser percebida sem equívocos pelo usuário. $\mathrm{O}$ princípio determina que a informação deve ser mostrada de maneira tal que possa ser percebida (através da visão ou de outro sentido), fácil e rapidamente, sem possibilidades de confusão.

A estrutura é um dos elementos determinantes da qualidade de um documento digital, combinando elementos das linguagens naturais com uma linguagem não-natural, que necessita da observância a formalismos. Os sistemas de leitura de tela exigem que haja a observância à estrutura do documento, nas etapas de projeto e construção do documento digital, para que eles tenham significado como informação. Isso exige que alguns cuidados sejam tomados, tais como a denominação atribuída a cada campo de enlace, os quais devem ser concisos (escritos sem abreviaturas) e significativos, de forma tal que fique explicado, ao usuário, para qual parte do documento será conduzido se optar por esse enlace. Os enlaces externos devem receber atenção especial e ser informados ao usuário, por constituírem espaços cuja acessibilidade foge ao controle dos autores do conteúdo digital no qual foi iniciada a navegação.

Embora o documento digital possa ser um hipertexto, o processo de leitura de um documento, pelo sistema de leitura de tela, obedece a uma seqüência, o que exige que as informações contextualmente relacionadas estejam agrupadas de forma que possam ser acessadas numa mesma vizinhança.

Os ícones constituem outro ponto de verificação importante, pois devem permitir que o usuário faça uma rápida associação com o seu significado, ser facilmente diferenciados entre si e estar adequadamente rotulados. Os ícones devem ser usados apenas como recurso alternativo de redundância à barra de menu, ou seja, é necessário que o usuário possa interagir com o ambiente também sem o uso dos ícones.

O conteúdo semântico das mensagens e o uso de uma linguagem simples são componentes não-estéticos que agregam qualidade a um texto digital.

Entre os componentes estéticos que contribuem para a clareza do documento, encontram-se a formatação adotada para o texto (fonte, tamanho, etc.) a quantidade de informação exposta na tela, o conforto e a legibilidade do contraste utilizado entre o texto e o seu fundo. Alguns cuidados estéticos podem contribuir para que os textos digitais ofereçam melhor legibilidade, entre os quais podese relacionar: o emprego de fontes sem serifa, o tamanho mínimo de 12 pontos para as fontes, a utilização de letras minúsculas na composição das frases e a adoção de espacejamento duplo para os parágrafos.

A figura 6 exemplifica alguns desses conceitos presentes no texto de divulgação de um congresso. À esquerda mostra-se o sítio Web, com a aparência convencional, e, 
Conteúdos digitais multimídia: o foco na usabilidade e acessibilidade

à direita, apresenta-se parcialmente a estrutura de enlaces do mesmo, conforme será apresentada àqueles usuários que acessem esse sítio Web utilizando um sistema de leitura de tela. Observa-se que o nome atribuído a cada um dos links (esse nome será lido pelo SLT) tem conteúdo semântico equivalente ao que é percebido por uma pessoa que lê a página visualmente.

\section{Priorização da funcionalidade e da informação}

Efeitos sonoros, de animação e de realce visual podem ser usados na elaboração de conteúdos digitais, desde que a carga de informações contida neles possa ser acessada também em sua ausência. Isso determina que sejam tomados alguns cuidados na preparação dos conteúdos digitais, como os destacados a seguir.

A cor não pode ser o único recurso utilizado para indicar ação ou significado, ou mesmo para destacar palavras em um texto. Expressões como "escolha o botão verde para continuar ou o vermelho para cancelar" não são eficientes para transmitir informação, pois há de se considerar os usuários que utilizam vídeos monocromáticos ou com deficiência visual (daltonismo, baixa visão, cegueira). Toda informação transmitida com o uso de cores deve estar disponível também sem o uso das cores.

Os elementos e informações mais importantes do texto devem estar evidenciados, para facilitar ao usuário o acesso à informação de seu interesse. Recursos estruturadores do documento, tais como índices, títulos e marcadores, podem ser empregados. Blocos de informação extensos podem ser apresentados resumidamente, permitindo ao usuário o conhecimento prévio da estrutura geral do documento de forma tal a que possa passar, com segurança, às partes de seu interesse.

A redação do texto também merece atenção especial, e, para obter uma usabilidade adequada, é necessário observar alguns cuidados, tais como apresentar por extenso das siglas, evitar o uso de abreviaturas e só utilizar aquelas que sejam bem conhecidas e não gerem dúvidas, abolir o uso de palavras que ocasionem cacofonias, as quais poderão prejudicar a compreensão do texto quando se utilizarem sistemas de leitura de telas, e empregar corretamente a pontuação, entre outros .

Entre as etapas de construção de um texto digital que tenha usabilidade, consta, necessariamente, a etapa de revisão mediante sistemas de leitura de tela, tanto para o aperfeiçoamento quanto para a verificação da acessibilidade dos conteúdos apresentados. É isso que irá garantir a priorização e o acesso à informação contida no texto.

\section{Transferência de tecnologia}

Esse princípio estabelece que um produto, uma vez criado e após demonstrada sua eficiência e eficácia, pode ser apropriado por outros usuários além daqueles considerados público-alvo na sua concepção.

Na produção de conteúdos digitais, deve-se observar que a tecnologia dos sistemas de leitura de tela, inicialmente concebida tendo como foco de atenção as pessoas com deficiência visual, está sendo transferida a outros usuários, como pessoas disléxicas, com deficiência motora e com deficiência cognitiva, sendo, portanto, imprescindível que a qualidade dos conteúdos digitais produzidos seja verificada também no que diz respeito à sua utilização por pessoas que utilizam essa ajuda técnica.

\section{Auto-explicação}

Esse princípio estabelece que quando um produto é bem projetado, o usuário aprende a trabalhar com ele à medida que vai interagindo com o mesmo. Se o produto é um ambiente de aprendizagem, ou um conteúdo digital específico, pessoas com deficiência visual ou auditiva podem ter dificuldades para perceber as informações apresentadas pelo computador, conforme a mídia utilizada, embora interajam com autonomia em ambientes com interfaces bem projetadas. Pessoas com deficiência de coordenação motora, embora não tenham dificuldades para a percepção das informações expostas em determinada tela, podem ter muitas dificuldades para a interação com um ambiente mal-projetado, por exemplo, em um que exija freqüentemente a mudança de uma tela para outra.

Para que a qualidade de auto-explicação do produto seja plena, é necessário que ele seja projetado obedecendo aos princípios do design for all e que seja compatível com o uso das ajudas técnicas informáticas.

\section{Considerações finais}

À medida que aumenta o volume de informação divulgada no espaço digital, as pessoas vão percebendo que, além de consumidoras, podem ser produtoras de informação e, por sua vez, esta última pode ser considerada como um produto. No que diz respeito a produtos de outra natureza, esses papéis são bem separados e, dificilmente, uma pessoa que é consumidora de um produto, ou usuária de um serviço, considera-se responsável pela produção do mesmo, pois existem 


\section{Elisabeth Fátima Torres / Alberto Angel Mazzoni}

profissionais especializados nesses misteres. No que diz respeito aos conteúdos digitais isso é diferente, pois, com as ferramentas atualmente disponíveis, mesmo pessoas com poucos conhecimentos sobre informática podem desenvolver conteúdos em suas áreas de interesse, ou então contratar pessoas que o façam, assumindo, portanto, o papel de produtores desses conteúdos digitais.

Um dos aspectos importantes a serem observados na produção de conteúdos digitais nos dias atuais, quando a informação é caracterizada como uma riqueza, diz respeito às condições de acessibilidade à mesma. Esse conceito tem sido desenvolvido a partir das recomendações elaboradas pelo W3C para páginas Web.

Tanto o produtor quanto o consumidor são sujeitos ativos no processo de elaboração de um produto conteúdo digital, estando, portanto, comprometidos com a qualidade do mesmo. É importante que, sempre que se for avaliar a usabilidade de um produto que tenha conteúdo digital, os consumidores apliquem o mesmo rigor com que avaliam os demais produtos que consomem. Além disso, deve-se considerar a acessibilidade como parte indissociável da aferição da eficiência e eficácia do produto "conteúdo digital" e, para que isso ocorra, quando a avaliação do produto não for explícita quanto a esse requisito, faz-se necessário que os consumidores incluam a avaliação do requisito "acessibilidade", quando expressam seu nível de satisfação com algum produto que tenha conteúdo digital.

A participação do consumidor na etapa de avaliação, indispensável para o aperfeiçoamento do produto, faz com que ele seja também responsável, juntamente com os profissionais da equipe de produção, pelo fato de esse conteúdo digital específico possa estar inacessível a muitas pessoas, por não contemplar critérios de usabilidade e de acessibilidade.

Cabe lembrar que a multimídia não constitui uma adversária da acessibilidade. Ao contrário, é com a utilização dos recursos propiciados por ela que a acessibilidade em conteúdos digitais pode ser alcançada. Usabilidade e acessibilidade agregam qualidade a um produto e representam direitos do consumidor e, como tais, devem ser respeitados e praticados por todos.

Artigo recebido em 26-07-2004 e aceito para publicação de 18 a 21/10/2004.

\section{REFERENNCIAS}

BERLENGA, Ana I. S. Boas práticas: da identificação à disseminação. Lisboa : INOFOR, IEFP, 2000.

GUTIÉRREZ RESTREPO, E. Accesibilidad digital: lista mantida pelo World Bank. Disponível em: <inclusiva@lists.worldbank.org>. Acesso em: 2 maio 2003.

JORDAN, Patrick W. An Introduction to usability. London : Taylor \& Francis, 1998.

TORRES, Elisabeth F. Usabilidade e acessibilidade de conteúdos digitais. In: CONGRESSO NACIONAL DE AMBIENTES HIPERMÍDIA DE APRENDIZAGEM, 1, 2004, Florianópolis. Anais... Florianópolis : UFSC, CTC, 2004. CD-ROM.

RUIZ-VELASCO, E. Algunos elementos para orientar el uso y la producción de contenidos con certidumbre y calidad. In: SIMPOSIO VIRTUAL SOMECE, 2003. Anais... [S. 1.] : Sociedad Mexicana de Computación en Educación, 2003. Disponível em: <http:// www.somece.org.mx/simposio2003>. Acesso em: 10 dez. 2003. 